\title{
The State of Sea Systems and Practices in East and Southern Africa
}

\author{
Cristina Rebelo, José Guerreiro \\ Centro MARE, Faculdade de Ciências da Universidade de Lisboa, Campo Grande, Edifício ICAT, Portugal \\ Email: cristina.rebelo@fc.ul.pt, joseguerreiro2958@gmail.com
}

Received 17 December 2015; accepted 23 February 2016; published 26 February 2016

Copyright (C) 2016 by authors and Scientific Research Publishing Inc.

This work is licensed under the Creative Commons Attribution International License (CC BY). http://creativecommons.org/licenses/by/4.0/

(c) $\underset{\mathrm{EY}}{\mathrm{i}}$ Open Access

\section{Abstract}

This paper develops a comparative overview of SEA in Kenya, Tanzania and South Africa regarding legal, institutional and procedural perspectives, in order to assess their effectiveness and unveil main constrains. It is clear from this brief review that SEA is a tool of environmental governance that is of growing importance in East and Southern Africa. With regards to the institutional and legal framework, both Kenya and Tanzania have formal provisions for SEA, but no specific legislation. The main constrains on SEA effectiveness are related to the lack of a clear mandate and institutional framework, guidelines for procedures and public participation. As this analysis and case studies from the three countries examined here reveal, Kenya, Tanzania, and South Africa have expanded their use of SEA as a preventive mechanism for environmental policy and to enhance the efficiency of strategic decisions. While each of these countries has made great strides in developing the SEA process and integrating it into their decision-making processes, much work remains to be done. Ongoing refinement to the SEA process, both within this region and elsewhere in the world, will mean that this important tool integrates sustainable environmental management principles and practices into policies, plans, and programmes and the decision-making process.

\section{Keywords}

Strategic Environmental Assessment, East and Southern Africa, Comparing SEA Systems and Practices

\section{Introduction}

Strategic environmental assessment (SEA) is recognised as an important decision support tool for integrating environmental considerations along with social and economic considerations into proposed policies, plans and 
programmes [1]. A recent classification attempted [2] [3] identified the following SEA models:

- Environmental Impact Assessment (EIA) Based: SEA is often carried out under the requirements of EIA legislation. It follows the EIA approach and uses similar tools.

- Dual Track: The SEA process and its procedures run in parallel, but independently from the policy-making and planning processes.

- Integrated: SEA is part of policy-making and planning.

- Decision-Centred: The planning and policy-making processes determine the SEA framework, which is adapted and customised accordingly to insure a close fit with the requirements of strategic decision-making.

Although countries may be grouped under a single model, their SEA frameworks are not similar due to national particularities in legal and institutional structures, and procedural arrangements. However, only a fine line differentiates the characteristics of each model [1].

SEA practice has been expanding internationally at a rapid rate in both developed and developing countries [4] [5] at different levels of the decision-making [6]. Internationally, SEA has been endorsed in two important documents, namely, the European SEA Directive (2001/42/EC) [7] and the United Nations Economic Commission for Europe (UNECE) 2003 SEA Protocol [8]. Moreover, international financing institutions and cooperation organisations are introducing their own SEA procedures and requiring beneficiary countries to adopt and include SEA procedure into their planning and decision-making processes ${ }^{1}$.

Developing countries have introduced legislation or regulations to undertake SEA, usually through EIA laws or natural resource or sectoral laws and regulations [9]. East African countries have used SEA processes to evaluate a wide variety of public policies, programmes, and projects. While the SEA experience is limited in Kenya and Tanzania, South Africa has undertaken SEA voluntarily since the mid-1990s (more than 50 SEA have been identified), and is considered a regional model for SEA practice. The experience of these three countries with SEA is evaluated here as part of a project ${ }^{2}$ to provide guidelines and strategies to three East African states (Kenya, Tanzania, and Mozambique ${ }^{3}$ - Figure 1) looking to use mangrove ecosystems as part of a peri-urban sanitation system. This review provides a useful prototype for SEA evaluation with wider application to other regions in tropical zones with critical mangrove systems.

This paper provides a comparative overview of SEA systems and practices in Kenya, Tanzania, and South Africa from legal, institutional, and procedural perspectives in order to assess their effectiveness through critical review of selected case studies.

In particular, the following issues are addressed: Which concept of SEA is followed? Are SEA models followed effectively? What are the main constrains and gaps to effective SEA processes? Is there a pattern for an effective institutional framework and procedural arrangements for SEA processes? What are the next steps for improving existing SEA systems and practices in these three countries?

\section{Methodology}

A two-step methodology was used in this research. First, a comparative assessment of SEA in the selected countries was carried out through the evaluation of their legal, procedural, and institutional frameworks.

Second, since case studies are particularly suitable for SEA process evaluation, several case studies were selected from Kenya, Tanzania, and South Africa and performance evaluation criteria were developed. For the selection of the case studies, the following criteria were considered:

- the case study was a completed process, or a process near completion, such that sufficient information was available and there was an opportunity to explore the real and potential benefits of the application;

- there must be sufficient evidence to label the work as a strategic level assessment or SEA-type application;

\footnotetext{
${ }^{1}$ Is for example the case of the World Bank.

${ }^{2}$ PUMPSEA (project no. INCO-CT2004-510863) was a 3-year research project funded by the European Commission through its $6{ }^{\text {th }}$ Framework Programme applied in Mozambique, Tanzania and Kenya (www.pumpsea.icat.fc.ul.pt). The filtering capacity of mangrove ecosystems was the basis for the PUMPSEA Project. The overall objective was to demonstrate the ecological and economical service that peri-urban mangroves can provide by mitigating coastal pollution through sewage-filtration, and to offer innovative solutions for the exploitation and management of this ability. The Project examined two innovative ways in which mangrove filtration can be utilized to preclude coastal sewage pollution: facilitating sewage filtration by conserving filtering mangroves and replanting mangroves in deforested areas exposed to sewage ("strategic reforestation and conservation"), and using constructed mangrove wetlands for sewage treatment.

${ }^{3}$ As Mozambique does not have any formal provisions for SEA, or specific legislation, and from site research it was not possible to identify any SEA-type applications, it has been excluded from this analysis.
} 


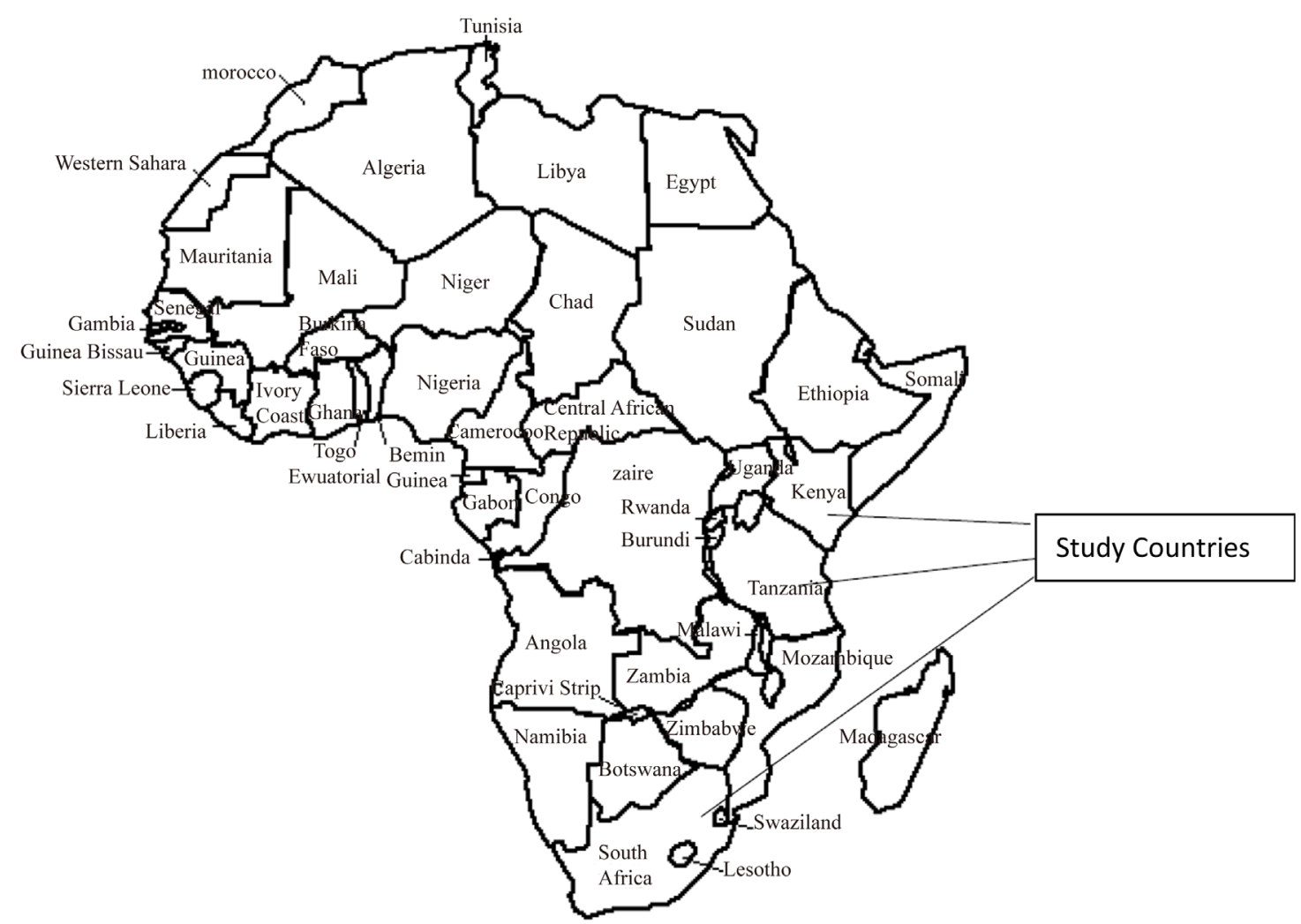

Figure 1. Study countries: Kenya, Tanzania, South Africa.

- the case study was conducted by different institutions (for each country), in order to assess main differences. The case studies were selected from a total of 60 SEAs identified with a view to balancing specific SEA principles and criteria details and the breadth of SEA experience across Kenya, Tanzania, and South Africa ${ }^{4}$. The case studies represent three different types of SEA processes: comprehensive, conservation, and water management.

The intent here is not to comparatively evaluate SEA cases, rather to explore each case on the basis of a variety of criteria deemed to be characteristic of desirable SEA models and frameworks. The analysis of each case study followed a two-step approach:

- a description of the respective SEA framework and/or application;

- a review of the SEA framework and/or application against proposed criteria, based on the case study documents and supporting literature.

The case studies performance evaluation methodology applied to this research was adapted from Noble [10].

The criteria are separated into system, process and results criteria as follow:

System Components

- Provisions: Clear provisions, standards or requirements to undertake the process.

- Tiering: Assessment is undertaken within a tiered system of environmental assessment, planning and decision-making.

- Sustainable development: Sustainability/sustainable development as a guiding principle and integral concept. Process Components

- Responsibility and accountability: Clear delineation of assessment roles and responsibilities; Mechanisms to ensure impartiality/independence of assessment review.

- Purpose and objectives: Assessment purpose and objectives are clearly stated.

${ }^{4}$ Two additional case studies were conducted and inform the discussion and conclusion to this paper but their details are not included here. These are the North West Spatial Development Framework (South Africa) SEA concerning integration of the concept of sustainability with provincial land use planning and the Rustenburg (South Africa) SEA concerning identification of a strategic framework for economic (specifically mining) development decision-making. 
- Alternatives: Comparative evaluation of potentially reasonable alternatives and scenarios.

- Impact evaluation: Identification of potential impacts or outcomes from each option or scenario under consideration.

- Monitoring programme: Procedures to support monitoring and follow-up of process outcomes and decisions for corrective action.

- Participation and transparency: Opportunity for meaningful participation and deliberations. Results Components

- Decision-making: Identification of a "best" option or strategic action; provides sufficient information for decision-making.

- Influence: Defined linkage with assessment and review or approval of any anticipated lower-tier initiatives; identification of indicators or objectives for related or subsequent strategic initiatives or activities.

- System-wide learning: Opportunity for learning and system improvement.

\section{SEA Systems and Practices in Kenya, Tanzania, and South Africa}

\subsection{Legal Provisions}

Formal provisions for SEA can be made under EIA or other legislation, or separate administrative orders or policy guidelines. Generally, SEA systems that apply to plans and programmes are based or modelled on EIA legislation, and follow the same or comparable requirements and procedures [11]. This is the case for Kenya and Tanzania where formal provisions for SEA are included in the Environmental (Impact Assessment and Audit) Regulations [12] and in the Environmental Management Act [13], respectively. SEA is performed for the three tiers of strategic decisions, namely policies, plans and programmes.

South Africa uses SEA on an ad hoc basis to assist in policy formulation [11]. South Africa has a voluntary SEA system and thus does not implement SEA according to a legally-prescribed process. Nevertheless, several policy initiatives address the need for SEA, including the White Paper on Environmental Management Policy for South Africa [14] and a discussion document entitled "A National Strategy for Integrated Environmental Management (IEM) in South Africa” [15]. The National Environmental Management Act No 107 of 1998 (Republic of South Africa) [16] as amended ${ }^{5}$ includes provisions for assessment procedures to ensure that the environmental consequences of policies, plans and programmes are considered. In addition, South Africa has two SEA guidance documents: the Strategic Environmental Assessment in South Africa-Guideline Document [17], which sets out, inter alia, best practices and a generic approach to SEA, and the Strategic Environmental Assessment Guidelines, Integrated Environmental Guideline Series 4 [18], which provides detailed guidance on key elements of the SEA process, rather than a prescriptive step-by-step process. SEA is used at the three levels of strategic decision-making.

\subsection{SEA Procedural Framework in Kenya, Tanzania, and South Africa}

Screening is undertaken to determine the potential of a policy, plan or programme to significantly impact the environment and thus to decide whether or not a SEA is required. While screening methods and techniques will vary according to the nature and the objectives of the proposal and the decision-makers' need, the SEA process must remain focused on key strategic issues and take into account capacity constraints. The practice exists in all three countries, however, only South Africa screens using a positive list.

Scoping determines the nature and extent of the SEA, identifying the key environmental issues and alternatives at a strategic level that which should be investigated in more detail. Stakeholder engagement, including specialists and authorities, is a key technique for identifying strategic issues [17]. In Kenya and Tanzania, the Environmental (Impact Assessment and Audit) Regulations and the Environmental Management Act [12] [13], respectively, do not include requirements regard scoping. However, from the literature review, we have determined that the practice exists. In South Africa, the two SEA Guidance documents provide a detailed description of scoping process [17] [18].

Public involvement in the SEA process ranges from merely being informed on the SEA process, to providing inputs or being actively involved in influencing the process. The public participation process should be designed

\footnotetext{
${ }^{5}$ The National Environmental Management Act makes provisions for the development of assessment procedures that aim to ensure that the environmental consequences of Policies, Plans and Programmes (PPPs) are considered.
} 
in such a way that it enhances the entire SEA process [17]. All three countries have introduced some form of public participation in their SEA process.

All three countries require the consideration of alternatives to the proposed policy, plan or programme. However, even in the case of South Africa, few details on the type or hierarchy of alternatives (need/demand, mode/ process, location, and timing/implementation) or minimum requirements regarding scenario identification are provided. Likewise, each of the countries has stipulated requirements for indicating measures to reduce or mitigate the potential significant effects on the environment of the proposed strategic action, with those from South Africa being the more detailed.

Finally, SEA review is practised in both Tanzania and South Africa. The review evaluates the positive and negative aspects of the framework for sustainability and the final draft of the plan or programme. The review step is a means to monitor the quality of the presented information, which is the basis for decision-making, and thereby pre-determines the suitability, practical feasibility, and sustainability of the resulting strategic action.

\subsection{Institutional Framework in Kenya, Tanzania, and South Africa}

A clear mandate and institutional framework setting out the lead institution is vital to the SEA process. The institutional framework will pre-determine the leverage points for SEA inputs in the planning and decision-making process, the focus of SEA, coordination and consultation opportunities, facilite public and stakeholder participation, and provide a map of procedural arrangements. Figures 2-4 set out the institutional framework in Kenya, Tanzania and South Africa respectively.

In each country, the SEA is initiated by the proponent authority. In Kenya, the party responsible for conducting SEA is also the proponent authority (the ministry responsible for the PPPs); in South Africa, it is a prequalified environmental assessment practitioner. In Tanzania the SEA is conducted on the basis of the nature of the project under consideration. In cases involving mineral or petroleum resources, hydro-electric power stations, or major water projects, the ministry responsible for mining, energy or water carries out the SEA. For all other cases, the SEA is carried out by the ministry responsible for matters relating to the environment.

South Africa and Tanzania require a review of SEA findings. In Tanzania, the Director of Environment reviews the SEA statement and submits a review report to the minister responsible for matters relating to the environment. In South Africa, according to the two Guidance documents [17] [18], the review is required, although responsibilities are not assigned to specific government authorities to perform the review. The review process can include relevant authorities, specialists, and interested and affected parties.

\section{Case Studies: A Critical Review of the SEA Process in Kenya, Tanzania, and South Africa}

Collectively, the cases reviewed here illustrate a range of SEA experiences and models across the three African countries under a variety of assessment systems and planning frameworks. The lessons learned from each of these SEA processes contribute to development of a more robust and effect SEA model for these countries.

\subsection{Kenya Forests Act 2005 (Kenya)}

Forests in Kenya are an important source of livelihood, environmental services, and economic growth. Traditionally, the government assumed full management responsibility for gazetted forest reserves [19]. In November of 2005, the Government of Kenya ratified a new Forests Act that emphasizes partnerships with community associations, the engagement of local communities, and promotion of private investment. An institution-centred SEA (I-SEA) was undertaken to inform and influence the process of implementing the new Act, to indirectly facilitate policy dialogue regarding sustainable use of natural resources for national development, and to draw lessons to refine future I-SEAs. It followed international good practice and the four-phase approach for I-SEAs supported by the World Bank: screening and scoping; situation assessments; setting environmental priorities; and development of alternative courses of action (Figure 5).

A noteworthy element of this I-SEA was its reliance on the active participation of a wide range of stakeholders, including community associations, through workshops and one-on-one discussions. This dialogue was essential in identifying key issues and priorities for action. In addition, the I-SEA acknowledged the adverse effects that shortcomings in existing legislation, and the institutional and governance weaknesses of previous ad- 


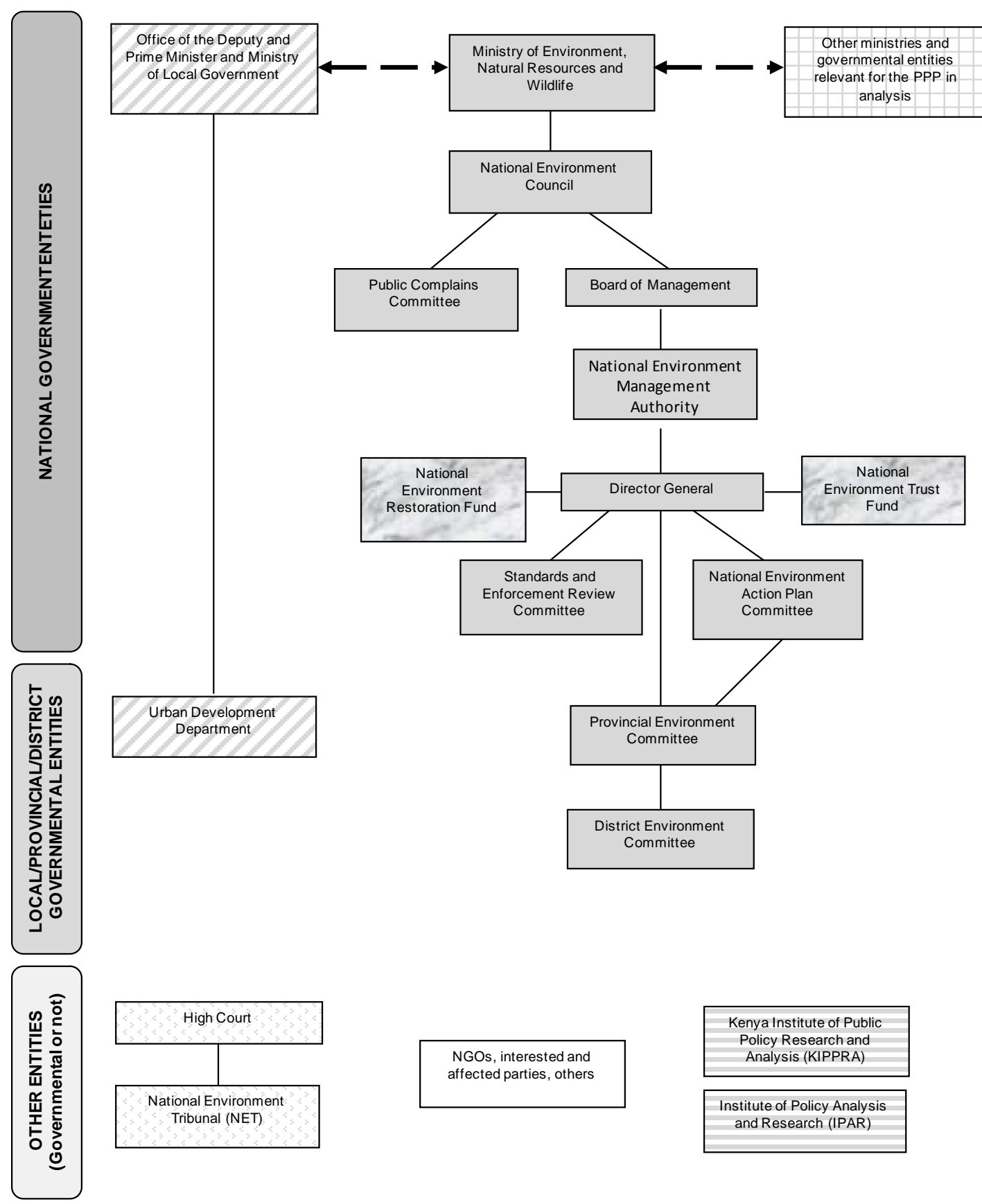

Figure 2. Organization chart representing the institutional framework of the SEA process in Kenya. Description: This figure shows all Kenyan institutions (governmental or not) involved in the SEA decision-making process. Legend: $\square$ Environmental policy, environmental management, environmental impact assessment, strategic environmental assessment; $\square$ Local government, coordination and support for local government authorities; $\square$ Other ministries and governmental entities relevant for the PPP in analysis; $\square$ Funds for research on environmental management, capacity-building, scholarships; $\square$ Resolves environmental disputes; $\square$ Research on policies.

ministrations have had on forest environments. Looking holistically at environmental, social and economic considerations, the I-SEA set out an informed and realistic policy action matrix. This matrix captured findings and recommendations and established clear timetables and responsibilities for action.

A report by the Government of Kenya [20] identified several lessons learned: 


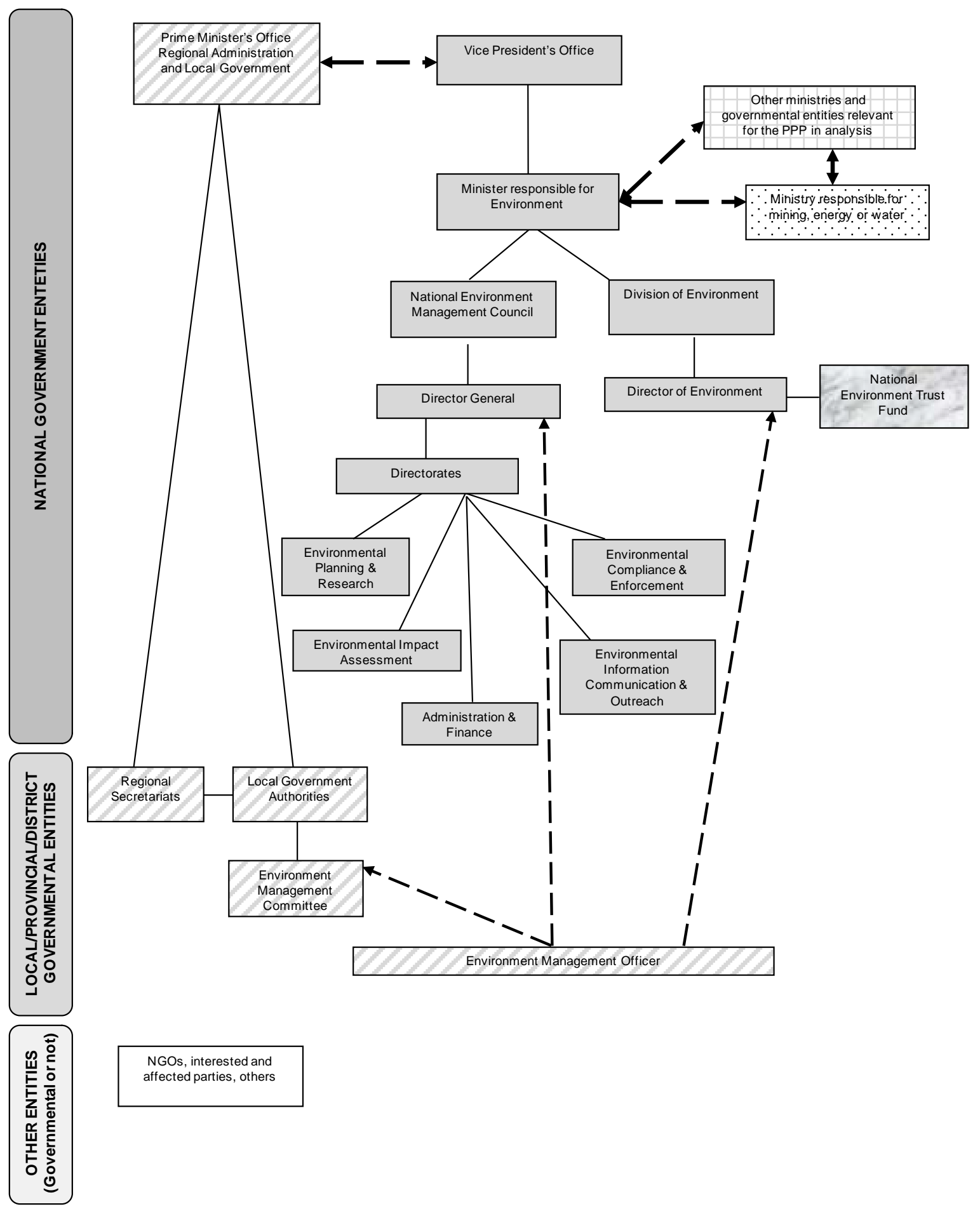

Figure 3. Organization chart representing the institutional framework of the SEA process in Tanzania. Description: This figure shows all Tanzanian institutions (governmental or not) involved in the SEA decision-making process. Legend: $\square$ Environmental policy, environmental management, environmental impact assessment, strategic environmental assessment; $\because \because$ Where mineral or petroleum resources is identified and before specific details are planned or a hydro- electric power station is planned or a major water project is planned the SEA is carry out by the ministry responsible for mining, energy or water. In the other cases is carry out by MER; $\square$ Local government, coordination and support for local government authorities; $\square$ Other ministries and governmental entities relevant for the PPP in analysis; $\square$ Funds for research on environmental management, capacity-building, scholarships. 


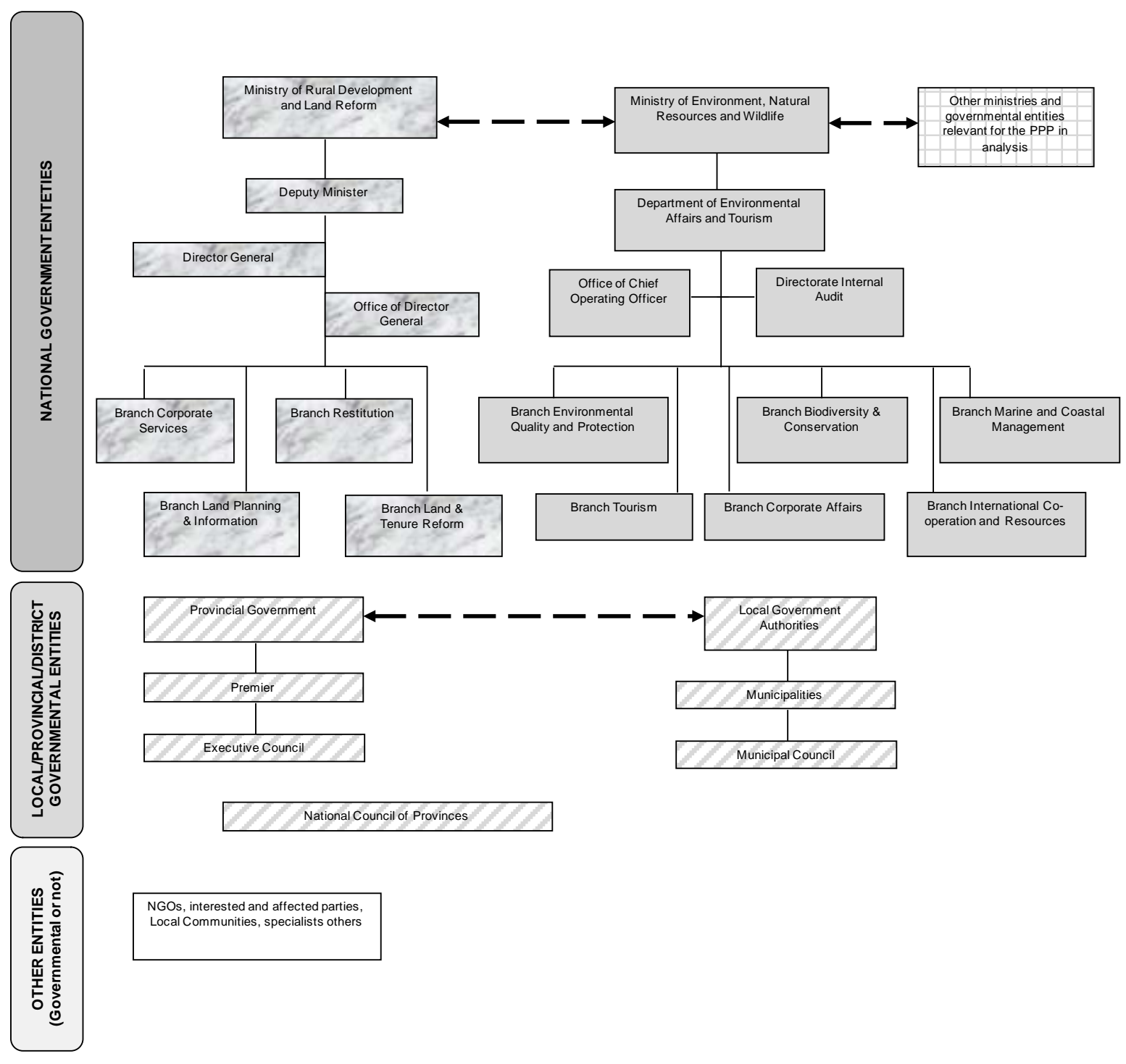

Figure 4. Organization chart representing the institutional framework of the SEA process in South Africa. Description: This figure shows all South African institutions (governmental or not) involved in the SEA decision-making process. Legend: $\square$ Environmental policy, environmental management, environmental impact assessment, strategic environmental assessment; $\square$ Land policy, rural development and rural reform; $\square$ Local government and provincial government; $\square$ Other ministries and governmental entities relevant for the PPP in analysis.

- The majority of stakeholders were unfamiliar with the concept of SEA, or its potential value to the reform process. This raises two important issues in planning future I-SEAs: What skills are needed for SEA?; and What level of support is needed in briefing and training stakeholders in their SEA role?

- The initial stages of setting up an I-SEA are critical, as is ensuring that relevant government ministries and agencies have endorsed and understand the process before work begins.

- Participation of at least one government official on the SEA consultancy team is necessary to strengthen ownership and continuity of the process and its implementation, to obtain the commitment of the relevant government departments, to facilitate access to government expertise, and to build long-term capacity for SEA. Stakeholder engagement and ownership of the process is essential to the success of a SEA.

\subsection{Future Dar es Salaam Water Supply Options (Tanzania)}

Dar es Salaam obtains most of its water from two offtakes on the Ruvu River, as well as the Mtoni River, and 


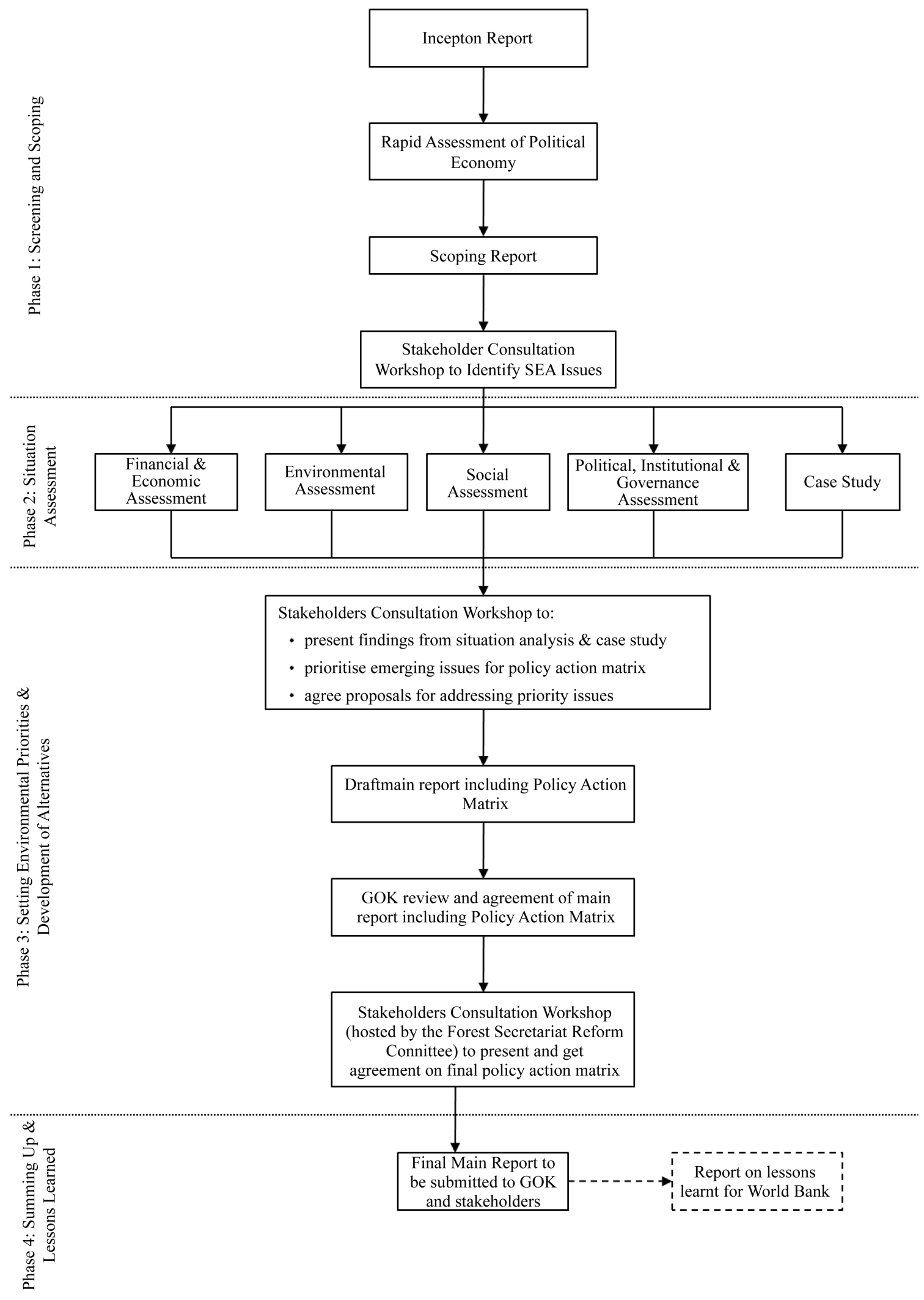

Figure 5. Kenya Forest Act (2005) SEA process (World Bank-ARDD, 2007). Description: The main steps of the Kenya Forest Act SEA process are shown in this figure. 
shallow aquifers. Continued population growth has made its water supply precarious, especially during the dry season when river levels fall. A long-term water supply master plan was drawn up [21] following a review of 26 surface and ground water, inter-basin transfer, and desalination options. The SEA ranked the 26 options in terms of their technical soundness, economics, and impacts and mitigation costs. The SEA was tiered to an EIA of each option by proposing the key social and environmental factors, as well as sensitive issues requiring special attention, to be addressed by an EIA; a preliminary strategy and work plan for undertaking an EIA; and the use of an international panel of experts to guide the EIA process. Although the SEA has narrowed the number of potential water sources to two, its influence on the choice of water supply is yet to be seen. However, this SEA illustrates the value of early integration of environmental and social criteria in the decision-making process and assessment of a wide range of options in a transparent manner.

\subsection{Tourism Development in the Northern Tourist Circuit of Tanzania}

This SEA was carried out to understand the likely environmental and social impacts of the tourist sector development plans in the Northern Circuit of Tanzania against sustainability objectives. Economic valuation of the potential sites and current tourist attractions was undertaken to assess the economic benefit of conserving these sites [22]. The economic valuation process demonstrated the considerable economic benefits accruing to the area, as well as the significant negative environmental impacts of the activities individually and cumulatively. The SEA also revealed the problem of enforceability of already existing guidelines on good practices for sustainable tourism development in the region.

\subsection{Transboundary Diagnostic Analysis and Strategic Action Program, Lake Victoria (East Africa)}

Lake Victoria, by area the second largest freshwater lake in the world, is experiencing social and environmental stresses including widespread watershed degradation, increasing water pollution, rising prevalence of water borne diseases, increasing conflicts over access to and use of natural resources, declining fisheries, loss of aquatic and terrestrial biodiversity, and more frequent and more severe droughts and floods. More recently, the rapidly declining lake levels as a result of hydropower generation have created serious social, ecological, and economic problems and political tension in the region [23].

Numerous international donors have stepped in to provide assistance to the riparian and basin governments address these issues. The largest and most complex of these projects was the World Bank managed Lake Victoria Environmental Management Project (LVEMP) towards which the Global Environment Facility (GEF) contributed [24]. The GEF/IDA funded project ran from 1996 to 2002 (Tanzania) and 2005 (Uganda and Kenya). This SEA represents the only transboundary process reviewed in this analysis and offers special insights into the SEA process in transboundary situations.

Although a mutually-agreed vision statement laid the basis for cooperative management of the lake basin, it fell short of providing a prioritized list of issues to be tackled through a coordinated programme of action by the basin countries. Consequently, GEF funded the Lake Victoria Development Program to produce a regional Transboundary Diagnostic Analysis and Strategic Action Program (TDA/SAP) between 2004 and 2007 as a foundation for the formulation of the second phase of the LVEMP.

A two-step process was used to develop the TDA/SAP. In the first stage, national TDAs were produced identifying the major priority transboundary issues using various tools and information sources in each country and these were ranked on the basis of each country's perception. In the second stage, these national priorities were reviewed regionally on the basis of the spatial extent of both environmental and socioeconomic impacts. Their root and immediate causes were investigated through causal-chain analysis, which included identification of institutional, legal, and policy issues that impeded their management. The regional SAP drew upon further stakeholder consultations, the national and regional TDAs and other material to identify a series of key transboundary issues.

Several lessons can be learned from this complex SEA process [23]:

- Complex transboundary projects such as this require that comparable methods, targets, and indicators are used in each country to identify and rank issues. Where there is great disparity in the size of the countries and the importance of the resource or ecosystem to each country's economy and social life (as was the case here), greater emphasis may need to be placed on some country's perceptions than others. Collation of national 
priorities into a regional priority provides an opportunity to correct some inconsistencies and omissions between the national priority setting exercises (e.g., TDAs), but that opportunity may not always be available.

- In this case study, the SEA was an externally required condition, which is not necessarily a strong foundation for ensuring implementation of the SEA recommendations. In this case, however, widespread government, professional and public support for sustainable development within the basin, through both multilateral and bilateral projects and the SEA process itself, provided an opportunity to structure common issues and responses.

- The two outputs from this project-the regional TDA and SAP-are overlapping and confusing. They use different terminology, structure priorities in different ways, and appear to be in competition in their attempts to identify priority issues.

- Although the level of stakeholder participation across the national TDAs, regional TDA, and SAP processes was commendable, it can skew the choice of issues and override the results of more analytical work. Both scientifically-based analytical information and stakeholder understanding and objectives need to be balanced in order to achieve a well-founded SEA process. The procedures used in transboundary SEAs must be carefully considered and agreed on to ensure that the recommendations represent the true importance of the issue to each country, e.g., in this case, the decline in lake level, which is of great economic and social importance to large population countries, was down-weighted in the regional TDA and SAP as equal weight was given to each national TDA and SAP.

\subsection{Water Use Study in the Mhlathuze Catchment in KwaZulu Natal (South Africa)}

Prior to 1994, SEA related to water resource management in South Africa focussed on conflicts arising from permitting for afforestation. A comprehensive consultation exercise initiated by the national Department of Water Affairs and Forestry (DWAF) indicated the need for a more holistic approach to permitting that extended the focus of SEA beyond forestry [25]. In 2000-2004, the DWAF, undertook a water use SEA that considered the biophysical, social, and economic impacts of the use and allocation of water in the Mhlathuze Catchment in KwaZulu Natal. The study initially focused on licensing water use for new forestation, but its coverage was expanded to include all water uses in the catchment, including the implementation of the concepts of the human and ecological water reserves [26] [27].

This study is an example of an impact-centred SEA, undertaken to obtain information for a subsequent plan. This SEA was intended to inform all levels of decision-making from project to policy level. However, the SEA lacked focus in key areas of the SEA process, e.g., data collection for the GIS and scoping objectives. The absence of institutional structures (i.e., a clear focus in the decision-making process) meant that it was unable to be tiered to project or plan levels, although it did enhance support for integrated water resources management at the programme level within DWAF, although not for the added value that SEA would bring to that programme [23].

A formal public participation process was conducted as part of the social analysis component and was considered a cornerstone of the SEA. Focused on communal rural areas because they represented the largest and neediest group, the participation process also included a stakeholder workshop attended by representatives of agriculture and industry. Attendance numbers suggests that the process was well received, although the non- alignment of catchment boundaries with institutional boundaries left pockets of the catchment area unrepresented. This case study demonstrates the importance of scale in the SEA process. The heterogeneity of the water management area mitigated against a single SEA study because each community had diverse water use objectives.

Overall, the lack of a clear objective, a focused client, and a well-designed work plan meant that this SEA did not lead to direct outcomes and that the initiative withered within the sponsoring government department.

\subsection{Addo Elephant National Park (South Africa)}

From humble beginnings in 1931 to protect the dwindling population of Eastern Cape elephants, South Africa announced ambitious plans for the Addo Elephant National Park (AENP) to integrate and extend existing conservation areas in the region. The new enlarged park would be the third largest national park in South Africa and cover six of the seven South African biomes, a potentially significant contribution to biodiversity conservation in Africa (adapted from CES [28] and Retief [25]). This SEA considered one overriding land use option, namely conservation, together with various options for boundaries and institutional and management strategies.

The goals of the SEA for the greater AENP were to synthesise existing socio-economic and biophysical in- 
formation, determine environmental opportunities and constraints presented by proposed expansion, recommend ways to optimize opportunities and minimise constraints, and to distribute this information to interested and affected parties, while at the same time highlighting World Bank Safeguard Policies. To ensure transparency in the planning process, the SEA encouraged stakeholders and other interested and affected parties to become involved in the process at an early stage.

Several lessons can be learned from this SEA:

- If a SEA is not integrated into the conceptualisation phase of a project or programme, it will be difficult for the SEA to purposefully influence important decisions concerning the vision and strategic objectives of that project or programme. Implementation of the SEA recommendations will also be determined by the SEA mandate and legal framework. Ideally, a SEA should be conducted within a clearly defined regulatory and institutional framework to ensure that outcomes are considered and incorporated into decision-making.

- A balance needs to be struck between conservation targets and socio-economic development priorities.

- Setting and communicating spatial boundaries must be stated clearly up front and communicated to those affected to avoid mistrust within the affected communities, which ultimately hampers buy-in to the project or programme.

- It is extremely difficult to consider trade-offs between bio-physical and social impacts if the scale and level of detail of the data differs. In the design of the SEA methodology, special consideration must be given to alignment of the different specialist studies to facilitate data integration.

\subsection{Analysis}

Collectively, these cases illustrate a range of SEA experiences and models across the three African Countries and under a variety of assessment systems and planning frameworks. Table 1 evaluates each case study against the system, process, and results performance criteria applied in this research (see Methodology above).

The case studies reveal that the major limitation in all the SEA processes examined here was the lack of a tiered system of assessment and decision-making that carries SEA results on to the next step. Only two cases provided for some form of tiering mechanism. If SEA recommendations are to be influential, SEA results must inform decisions inputs to the next tier, and SEA objectives must be informed by the decision outputs of previous tiers of assessment and decision-making. Only one of the case studies actually identified a 'best' option or strategic direction. An additional five cases partially met this criterion. In six case studies there was a clear delineation of assessment roles and responsibilities, but only one case partially met the criterion mechanisms to ensure impartiality/ independence of assessment review.

The consideration and assessment of a reasonable range of alternatives or scenarios, is a defining characteristic of SEA. This was clearly evident in the SEA of the Future Dar es Salaam Water Supply Options; in contrast, the Lake Victoria SEA did not provide any sort of comparative evaluation of alternatives and scenarios. The other cases demonstrated only a limited consideration of assessment alternatives. So, the potential for alternatives consideration is not equal under every SEA system or application. Additionally, although all three countries require the evaluation of environmental impacts, only the Dar es Salaam SEA identified the potential impacts or outcomes from each option or scenario under consideration. Five other cases met this criterion to some extent.

Finally, three case studies clearly demonstrated a formal, required programme for follow-up and monitoring of outcomes and decisions for corrective actions. All these three cases, interestingly, met the sustainable development criteria, and two of them met the participation and transparency criteria as well.

\section{Discussion}

It is clear from this brief review that SEA is a tool of environmental governance that is of growing importance in East and Southern Africa. Several conclusions and recommendations can be made on the basis of institutional framework, SEA procedures and practices, and case studies analysis that would improve the effectiveness of the SEA process and lead to better governance in these states and elsewhere. Four areas in particular warrant attention: the institutional and legal framework, public and stakeholder participation mechanisms, evaluation of impacts and the comparative evaluation of alternatives and scenarios, and finally, capacity-building in SEA.

With regards to the institutional and legal framework, both Kenya and Tanzania have formal provisions for SEA, but no specific legislation. South Africa has a voluntary SEA system and thus does not implement SEA 
Table 1. Case studies performance evaluation. Description: This table summarises the performance of the eight cases studies.

Evaluation criteria
Case studies $^{6}$

$\begin{array}{llllllll}1 & 2 & 3 & 4 & 5 & 6 & 7 & 8\end{array}$

SYSTEM COMPONENTS

Provisions

- Clear provisions, standards or requirements to undertake the process

* $\quad 0 \quad 0 \quad \square \quad \square \quad \square \quad \square$

- Assessment is undertaken within a tiered system of environmental assessment, planning and decision-making

Sustainable development

- Sustainability/sustainable development as a guiding principle and integral concept

PROCESS COMPONENTS

Responsibility and accountability

- Clear delineation of assessment roles and responsibilities

- Mechanisms to ensure impartiality/ independence of assessment review

Purpose and objectives

- Assessment purpose and objectives are clearly stated

Alternatives

- Comparative evaluation of potentially reasonable alternatives and scenarios

Impact evaluation

- Identification of potential impacts or outcomes from each option or scenario under consideration

- $\quad$ Procedures to support monitoring and

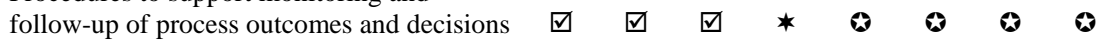

Monitoring program for corrective action

Participation and transparency

- Opportunity for meaningful participation and deliberations

RESULTS COMPONENTS

Decision-making

- Identification of a 'best' option or strategic action

- Provide sufficient information for decision-making

- Defined linkage with assessment and review or approval of any anticipated lower-tier initiatives

Influence

- Identification of indicators or objectives for related or subsequent strategic initiatives or activities

- Opportunity for learning and system improvement

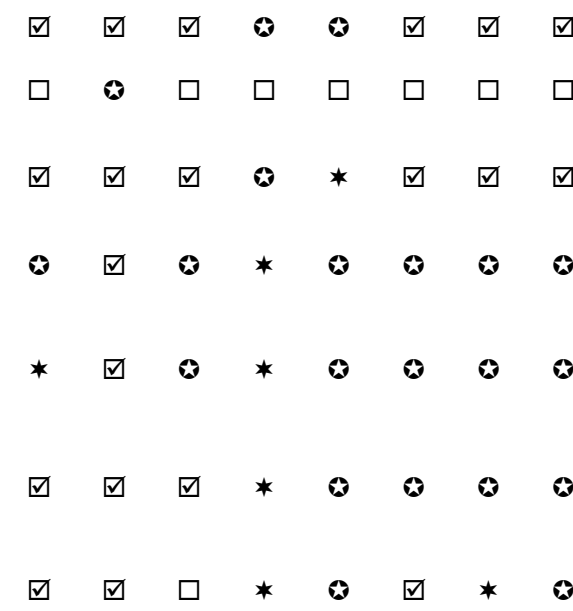

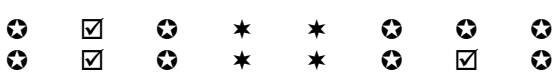

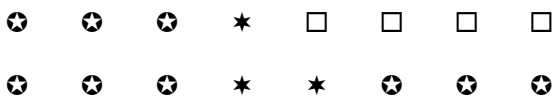

System-wide learning

■—criteria met; —criterion partially met; $\star$ —criteria not met; $\square$ —not able to determine or not applicable.

according to a legally-prescribed process. This duality of approaches meets the findings of Chaker et al. [1], who state that the option for a formal legal SEA or simply by "guidance" documents depends on the context of each particular country. Nevertheless, clear specific legislation would contribute to resolving some gaps, particularly the standardisation of the process components and institutional mandates. Because the existing institutional frameworks are complex, no clear mandate has evolved for each country's proponent authority. As a result, institutions involved in the SEA process often are unaware of their responsibilities and do not interact as they should. Thus, it is vital that the leading institution has a clear mandate and also that the institutional

${ }^{6}$ Case studies 7 and 8 are not discussed in the text above but inform the general discussion and conclusions of this article. See note 5 for details on these case studies. 
framework is well defined. From the literature review and field experience, we notice that it is not clear which institutions should be involved and when, as well as which are the interactions among them. This further reduces the effectiveness of the SEA process. Clarification of the legal provisions for SEA and the mandate for SEA proponents would strengthen the SEA framework in Kenya, Tanzania, and South Africa [29].

The SEA process in these three countries would also benefit from refinement of certain procedural refinements. The SEA process must be initiated as early as possible. Further, each SEA must have with a clear vision and strategic objectives, a focused client, and a well-designed work plan. The case study analysis here shows the lack of a tiered system of assessment and decision-making that carries forward SEA results to the next step of the process; this issue needs to be addressed in all three countries at all three levels of strategic decision-making. Additional improvements in screening and scoping procedures, particularly the use of positive lists, data collection and integration, and assessment of more than environmental and socioeconomic impacts (e.g., South Africa also evaluates health and cultural heritage impacts) would further strengthen the SEA process. Particular care must be taken to ensure that each country involved in a transboundary project uses comparable SEA methods and targets, as well as comparable indicators for identifying and ranking issues.

Keeping stakeholders engaged is an essential element to the success of a SEA. As these case studies reveal, stakeholder participation is still insufficient and clear mechanisms for their participation are lacking. Often stakeholders are unfamiliar with the concept of SEA. Additionally, public consultation is required during the SEA process. However, our analysis reveals that such consultation is often inadequate due to financial constraints, education, cultural differences, gender, and political and institutional decision-making cultures. These three African states are not alone in struggling with how to deal with these issues.

The review step is a means to monitor the quality of the presented information, which eventually will constitute the basis for decision-making and there-by pre-determine the suitability, practical feasibility, and sustainability of the resulting strategic action. Both South Africa and Tanzania require the review of SEA results. However, the Kenyan case study reveals that linkage of the assessment and review or approval processes with anticipated lower-tier initiatives is only partially met. It is worth noting that, in addition to technical information, political power may also play a role in shaping the final decision. The influence of non-technical political considerations could be expected to diminish as transparency and accountability in the decision-making process increases. The review process in each of the three countries analysed here could be improved. Additionally, the consideration of alternatives and other scenarios, which reflects the on-going debate and priorities regarding sustainable development and/or environmental sustainability, needs to be more fully integrated to these states' SEA process.

Enhancing capacity for application of SEA is a key issue worldwide. Training of SEA managers, technical specialists, stakeholders and others involved in the SEA process is essential for an effective SEA process, to improve standard practices, and ultimately, to improve outcomes. Developed and developing states need to work together in advancing education and training opportunities for SEA. It is also important that states work together to address the gaps and deficiencies in the literature documenting the practical implementation of SEA. Data regarding SEA procedures are insufficient and often incomplete, making it difficult to deduce lessons and capitalise on success stories. Indeed, for these three countries, there is almost no account or description of the obstacles and pitfalls (or successes) that have been faced in implementing SEA. Furthermore, there is limited information available regarding mechanisms to ensure independence of the assessment review process.

\section{Conclusion}

As this analysis and case studies from the three countries examined here reveal, Kenya, Tanzania, and South Africa have expanded their use of SEA as a preventive mechanism for environmental policy and to enhance the efficiency of strategic decisions. While each of these countries has made great strides in developing the SEA process and integrating it into their decision-making processes, much work remains to be done. Ongoing refinement to the SEA process, both within this region and elsewhere in the world, will mean that this important tool integrates sustainable environmental management principles and practices into policies, plans, and programmes and the decision-making process.

\section{Acknowledgements}

This study was carried out within the EU funded project PUMPSEA: Periurban mangrove forests as filters and 
potential phytoremediators of domestic sewages in East Africa. EU Contract no. 510863.

We would like to acknowledge the PhD grants to Cristina Rebelo (SFRH/BDE/15553/2005) provided by the Fundação para a Ciência e Tecnologia.

\section{Disclosure Statement}

The authors do not have any disclosure statement to proceed. All the authors have approved the final article.

\section{Role of the Funding Sources}

1) The EU Project "PUMPSEA: Peri-urban mangrove forests as filters and potential phytoremediators of domestic sewages in East Africa", EU Contract no. 510863, funded by the Sixth Framework Programme of the European Commission. European Commission was not involved in study design; in the collection, analysis and interpretation of data; in the writing of the report; and in the decision to submit the paper for publication.

2) PhD Scholarship founded by Fundação para a Ciência e Tecnologia attributed to Cristina Maria Caseiro Rebelo, first author.

3) This article is financed by Fundação para a Ciência e Tecnologia through the project UID/MAR/04292/ 2013.

\section{References}

[1] Chaker, A., et al. (2006) A Review of Strategic Environmental Assessment in 12 Selected Countries. Environmental Impact Assessment Review, 26, 15-56. http://dx.doi.org/10.1016/j.eiar.2004.09.010

[2] Partidario, M.R. (2003) Understanding SEA: What Is SEA and Why Is It Important? Presentation at the International Workshop on Strategic Environmental Assessment, Thailand, 18-20 November 2003.

[3] Partidario, M.R. (2003) SEA: Legal, Institutional and Procedural Models-A Global View. Presentation at the International Workshop on Strategic Environmental Assessment, Thailand, 18-20 November 2003.

[4] Dalal-Clayton, B. and Sadler, B. (2005) Strategic Environmental Assessment: A Sourcebook and Reference Guide to International Experience. Earthscan, London.

[5] Schmidt, M., Joao, E. and Albrecht, E. (2005) Implementing Strategic Environmental Assessment. Springer, New York. http://dx.doi.org/10.1007/b138661

[6] OECD (2006) Applying Strategic Environmental Assessment-Good Practice Guidance for Development Co-Operation.

[7] Directive 2001/42/EC on the Assessment of the Effects of Certain Plans and Programmes on the Environment. OJ L197, 21/07/2001, 30-37.

[8] Kiev (2003) UNECE Protocol on Strategic Environmental Assessment to the Convention on Environmental Impact Assessment in a Transboundary Context. http://www.unece.org/env/eia/sea_protocol.htm

[9] World Bank (2007) Strategic Environmental Assessment and Integrated Water Resources Management and Development. World Bank, Washington DC.

[10] Noble, B.F. (2009) Promise and Dismay: The State of Strategic Environmental Assessment Systems and Practices in Canada. Environmental Impact Assessment Review, 129, 66-75. http://dx.doi.org/10.1016/j.eiar.2008.05.004

[11] UNEP (2004) Environmental Impact Assessment and Strategic Environmental Assessment: Towards an Integrated Approach.

[12] The Environmental (Impact Assessment and Audit) Regulations, Kenya, 2002.

[13] The Environmental Management Act (2004) Gazette of the United Republic of Tanzania, No. 6, Volume 86.

[14] DEAT, Department of Environmental Affairs and Tourism (1998) White Paper on Environmental Management Policy for South Africa (South African Government Gazette No 18894, Notice 749 of 1998).

[15] DEAT (1998) A National Strategy for Integrated Environmental Management (IEM) in South Africa: Discussion Document (Pretoria, South Africa).

[16] DEAT (1998) National Environmental Management Act No. 107 of 1998. http://www.environment.gov.za

[17] CSIR, Council for Scientific and Industrial Research (2000) Strategic Environmental Assessment in South AfricaGuideline Document, DEAT, Pretoria.

[18] DEAT (2007) Strategic Environmental Assessment Guideline. Integrated Environmental Guideline Series 4, Department of Environmental Affairs and Tourism (DEAT), Pretoria. 
[19] World Bank-ARDD (Agriculture and Rural Development Department) (2007) Strategic Environment Assessment of the Kenya Forest Act 2005. World Bank, Washington DC.

[20] Government of Kenya (2007) Institution Centred SEA of the Forest Sector in Kenya-Lessons Learnt Report.

[21] World Bank (2007) Strategic Environmental Assessment: Enhancing Capacity for Integrated Water Resources Management and Development in Tanzania. World Bank, Washington DC.

[22] CEDR - Centre for Environmental Economics and Development Research (2003) The Sea of tourism Development in the Northern Tourist Circuit of Tanzania-CBBIA-IAIA Program.

[23] World Bank—ESWED (Economic and Sector Work Environment Department) (2007) SEA and Integrated Water Resources Management and Development. World Bank, Washington DC.

[24] Hecky, R. (2003) Lake Victoria Environmental Management Project: Phase 1. Scientific Stocktaking Report—Progress during LVEMP1 and Challenges for the Future. World Bank, Washington DC.

[25] Retief, F. (2007) A Performance Evaluation of Strategic Environmental Assessment (SEA) Processes within the South African Context. Environmental Impact Assessment Review, 27, 84-100. http://dx.doi.org/10.1016/j.eiar.2006.08.002

[26] DWAF (2000) Strategic Environmental Assessment for Water Use-Mhlathuze Catchment—KZN. Department of Water Affairs and Forestry, Pretoria.

[27] Steyl, I., Versfeld, D.B. and Nelson, P.J. (2000) Strategic Environmental Assessment for Water Use. Mhlathuze Catchment-KZN. Department of Water Affairs and Forestry, Pretoria.

[28] CES - Coastal \& Environmental Services (2002) Proposed Great Addo Elephant National Park—SEA Report, Volume 2.

[29] Rebelo, C. (2012) Avaliação Ambiental Estratégica e Avaliação de Impacte Ambiental na África Oriental: Um caso de estudo aplicado ao saneamento básico na zona costeira. PhD Thesis, Lisbon University, Lisbon, 268 p.

AENP: Addo Elephant National Park

DWAF: Department of Water Affairs and Forestry

EIA: Environmental Impact Assessment

GEF: Global Environment Facility

IEM: Integrated Environmental Management

I-SEA: Institution-centred Strategic Environmental Assessment

LVEMP: Lake Victoria Environmental Management Project

PPP: Policies, Plans and Programmes

SAP: Strategic Action Program

SEA: Strategic Environmental Assessment

TDA: Transboundary Diagnostic Analysis

TDA/SAP: Transboundary Diagnostic Analysis and Strategic Action Program

UNECE: United Nations Economic Commission for Europe 